\title{
THE DEVELOPMENT OF THE ONLINE FOREIGN LANGUAGE COURSE - THE EXPERIENCE OF THE BELL PROJECT
}

\author{
Marīte Opincāne \\ Rezekne Academy of Technologies, Latvia \\ Karīne Laganovska \\ Rezekne Academy of Technologies, Latvia
}

Iryna Kurbajeva

Belarusian Academy at the Higher School of Management, Konin, Poland

\begin{abstract}
Online acquisition of the foreign language has become particularly important lately, especially during and after the Covid-19 pandemic. In the framework of The European Union Capacity Building project "Enhancement of Lifelong Learning in Belarus" (https://bell-iln.by/en/) the online English course has been developed and implemented. The article summarises the professional experience of three parties. The main aim of this paper is to reflect the factors, which are essential for the development of an online foreign language course for adults. The following methods were used while doing the research: survey data analysis of project English language course's target audience and the qualitative analysis of the data content. A questionnaire of the course participants was developed and carried out, the answers were processed. The project experience was analysed, conclusions were drawn and the proposals for future work were worked out.
\end{abstract}

Keywords: online course, the acquisition of the foreign language, adult education, the framework of the project.

\section{Introduction}

The world and education are constantly changing, particularly after the Covid-19 pandemic when online learning and teaching became the main form of education. Mastering the foreign languages' acquisition, like any other sphere of life, requires more than the type of intelligence that makes a language learner successful. It requires the traits as the strong willpower, persuasiveness, and perseverance. There is a certain number of important factors in learning online independently. It relates to developing the online courses as well as maintaining the students so as not to lose them. These problematic issues have been made topical in the European Union Capacity Building project "Enhancement of Lifelong Learning in Belarus” (https://bell-iln.by/en/).

The community in Belarus at the moment is going through enormous changes and entering the western model from the socialist one. The importance of foreign languages has been increasing. That is why 6 regional Belarus universities collaborated and worked out 5 different online courses for the 
Belarus adult population. 4 regional European universities (from Latvia, England, Sweden, and Spain) were their partners and shared their experiences, assisted in the development of the courses, provided advice on their implementation, evaluated the courses, and also gave advice on their improvement. The partner universities themselves learnt a lot working on the project.

Professional experience of three parties has been summarised in the paper to the lessons learnt while working on the project as the project leader (Karine Laganovska, Latvia), the developer of the course (Iryna Kurbayeva, Belarus), and the language expert (Marite Opincane, Latvia). Summarizing the experience and the results acquired in the project, the conditions and requirements of the foreign language online course's development: the student's profile, the content and the structure of the course, time planning, the methods and forms of learning, application of teaching aids, the methods of knowledge and skills' evaluation and learning achievements have been discussed and analyzed.

The aim of the paper is to reflect the factors, which are essential for the development of the online foreign language course for adults. The methods of the research are as follows: the data analysis and the qualitative data content analysis of the project English online course's target audience.

\section{Conceptual framework of the research}

The talent to learn a foreign language is one of the main reasons why people are afraid to start studying a language. Someone is a high-level professional in the community but in the language classroom, s/he may feel like a school student who sometimes stammers out even the simplest ideas and cannot express his/her opinion. This is how a great number of adult students report having felt. But in the classroom, they are helpless in front of a teacher, they are scared to look ignorant. Adults can also often fear failure in the foreign language learning process. Meeting difficulties, they can give up, so the teacher's task is to help and encourage them.

Adult education has several aims. First, it allows students who, because of some reasons, were unable to complete their education to get their diplomas. Second, it provides an opportunity to the professionals in different spheres to improve their professional knowledge. Third, it gives a hand to those who plan to continue their studies or work career abroad. There are adults who want to study English in order to be able to communicate with the children-in-law and grandchildren who live abroad. Adult education is an inseparable part of education.

There is a great variety of English language learners. Most of them want to study communicative English and are not particularly interested in grammatical accuracy. There is a group of learners who are interested in learning English as a hobby and are not interested in serious acquisition of language skills. To sum 
up, adults have numerous reasons for studying a second or foreign language (SFL). This variety of reasons presents its own challenges to the teacher. Furthermore, the adults' learning process and its results have been influenced not only by the aims and motives put forward but also by their learning habits. Some of them do their best to use time and opportunities to acquire a thorough and deep knowledge, whereas others want to master the basic options of the language usage in order to use them in the future for the particular aims. Everybody has his/ her own learning style. Claudia Riemer and Kathrin Wild subdivide the learning antipoles as follows: the analytical versus the global one, the reflexive versus the global one, the ambiguity tolerance versus the ambiguity intolerance, the extrovert one versus the introvert one (Riemer \& Wild, 2018, 11). The management of cognitive learning peculiarities in the foreign languages' acquisition helps the teachers to choose the appropriate learning content and methodology.

Sharon Hilles and Andre Sutton emphasise that adult learners bring a great deal of life experience and cognitive maturity to the classroom (Celce-Murcia, 2014, 386). In a lot of cases, they already have a job, earn their living, bring up children, have seen life and have gone through many life difficulties. Adults direct their own learning process. In other words, if the learning environment does not match cultural expectations and perceived needs to some degree, the self-direction may take the form of challenging the teacher or syllabus in class, of filtering out what they perceive as nonessential. It can also result in simply leaving the class and seeking some other way of learning, or of abandoning the enterprise altogether. David Gosling has emphasised that all learners have different personal learning needs that must be met if they want to succeed. The development of learning is the way of meeting their needs (Gosling, 2009, 114).

Although they have their limited English proficiency, adults already have much more life experience, including the experience of learning other languages than school students. In addition to being mature and self-directed, adult learners are often more focused. As adults are often quite busy, participating in educational programmes, they can devote only a limited time to their learning. However, they are often highly dedicated students who approach learning seriously. Adults can also often fear failure in the foreign language learning process.

One of the challenges while developing an online course for foreign language acquisition is knowledge and the skill to develop the online course in order to make it appropriate to the broader range of the adults' audience. The adult audience is determined and motivated in its choice. The adults are aware of the necessity to learn a foreign language but sometimes these aims do not conform to the framework of the same programme. Some have chosen the course for professional purposes, others want to travel, or have some other aims. Similar situation was also in the group formed in the project framework. 
The Development of the Online Foreign Language Course - the Experience of the Bell Project

The results of the focus group's questionnaire will be discussed in the next part. They have revealed the essential details for the perfection of the developed online course.

\section{Procedure and results of the research}

The course "Pre- intermediate English" has been developed for people who are interested in learning English as a foreign language. It lasts for 16 weeks and consists of eight topics. Each topic takes two weeks. The material is distributed on six days a week, at the rate of one academic hour per day. Grammar and vocabulary are interrelated. The course will broaden learners' vocabulary, develop a better understanding of English grammar, and provide practice in developing of communicative skills. Language background of the future learners is elementary level. Having completed the course, students get 5 ECTS.

47 participants (32 women, 15 men) of the online course from 4 Belarus universities participated in the questionnaire on the evaluation of the English course. $85.1 . \%$ of them have a university degree, 5\% - incomplete higher education, $6.4 \%$ - secondary education. The questions on different aspects of the course evaluation were included in the questionnaire, but only those ones, which help to reveal the defined aim and emphasise the criteria, which assist in justifying of the course development criteria. This, in its turn could be useful in the development of any online foreign language course.

One of such issues was on the allocation of the learning time where a systematic and regular learning encouragement has been coded in the course design. 42 (89,4\%) participants when answered the question "Assess the timing of your distance learning programme!" considered that it was excellent and very good, $5(10,6 \%)$ - evaluated it as good. Based on the results of the project, we can make a conclusion that an online non-academic course should not be too long, up to 6 - 8 weeks. Otherwise, students get tired and lose interest. Keeping students motivated is the main issue.

It is vitally important for an online course to be carefully constructed and easy to navigate. As long as students do not have face-to-face interaction with teachers or peers, it is not always easy to stay organized and up to date with the course. They need to have time management skills. The distribution of materials by days and weeks disciplines students and sets them the correct pace of work. In our course, students are engaged 40 minutes a day six days a week but as the experience has shown, five days a week is an optimal schedule. Even distribution of the materials helps to keep the balance to neither overload or underload the students.

Therefore the questions of the questionnaire are concerned with the content and the structure of the course, the methods, and forms of organisation (How do you rate the content and the structure of the course? How do you assess the organizational forms of distance learning?). The answers acquired 
have been summarised in Figure 1 and they in general reveal high evaluation of the course content, although useful suggestions for its improvement were provided. For example, to provide a broader range of the language exercises in order to consolidate and perfect knowledge acquired. Also, to work more on communicative competence opportunities in the foreiogn language as the acquisition of reading and writing skills has been emphasised.

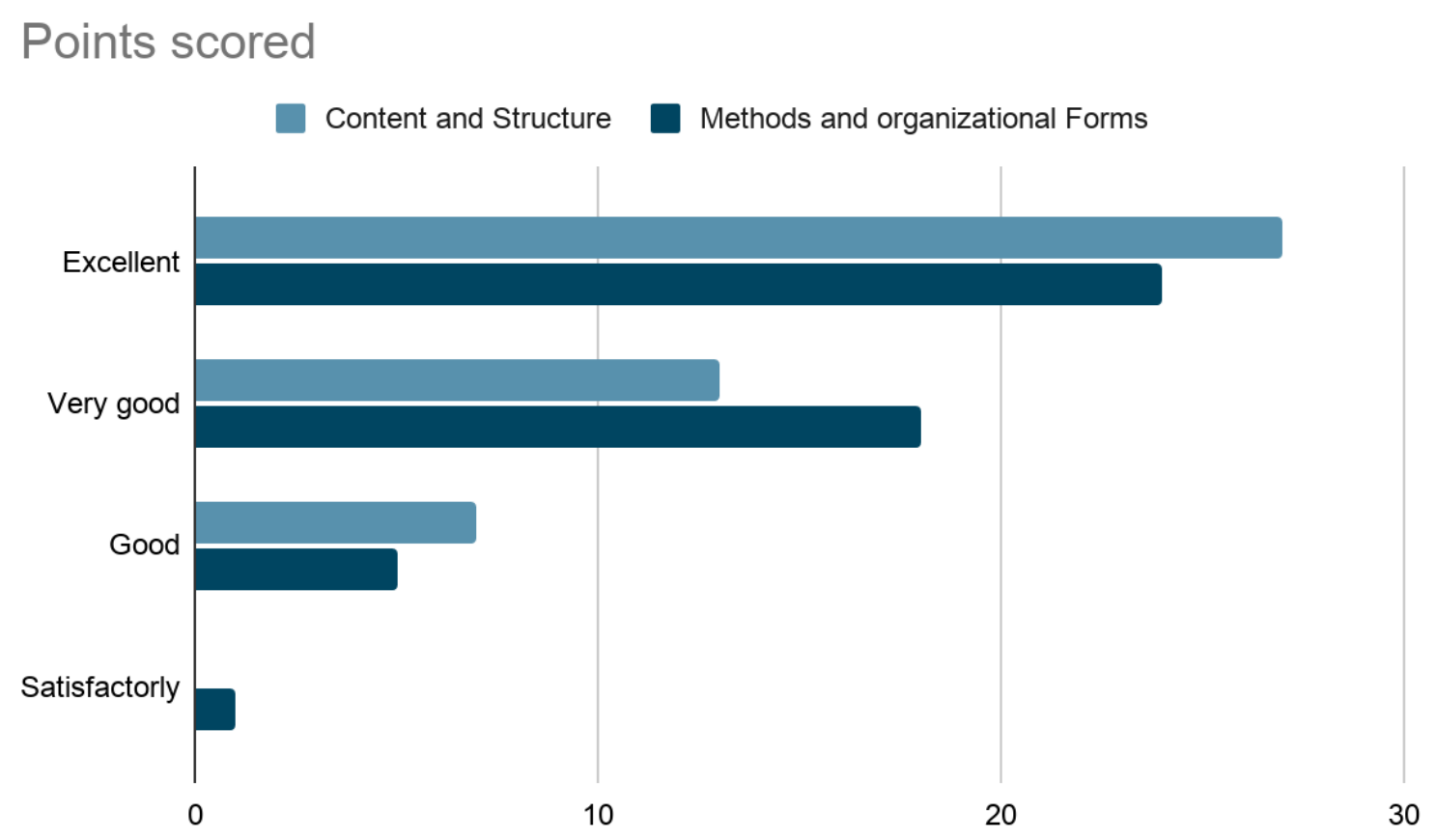

Figure 1 Evaluation of the Course Content

As the developers of the course consider, the most time-consuming part is developing of learning materials and placing them on the educational platform. Providing engaging and interesting content is not always easy as long as we must respect copyright. To address this issue, we have requested a written permission from copyright holders or created original content by the assistance of colleagues, other students, and native speakers. However, this part is also the most rewarding. Learning materials are estimated by our students as interesting, engaging, useful, and up-to-date.

While developing an online course, it is always necessary to bear in mind that learners will have to cope with the materials on their own. Instructions are to be clear, grammar explanations - easy and understandable, and exercises doable. At first, it seemed that explaining and practicing grammar was one of the most easily accomplished tasks. The BELL project modules have been developed on Moodle. The platform offers a wide variety of tools for developing of training exercises. However, piloting proved that the students experienced some difficulties with grammar comprehension. The grammar rules required 
The Development of the Online Foreign Language Course - the Experience of the Bell Project

more careful formulation, simplification, and clarification. It is better to avoid the exercises with the variable answers, as long as they have to be discussed and there is not always such an option for online learning. At the stage of developing the course, it was one of the especially helpful experts' recommendations to reduce the teachers' input and monitor the balance between teachers' support for the students during the module and peer support among the students, in order to maximise students' engagement and optimise teachers' input. The educational platform offers different instruments and tools to organise group or pair work. Some of them, like Forum, worked properly but it was still difficult to organise peer review for oral speech. Chat was tried, but students were supposed to be online at the same time and they found it difficult and inconvenient. So organizing oral speech practice was the most complicated part of work for both the developers and the students.

The questions on the correspondence of the learning results and aims, needs and intentions (Do the learning outcomes meet your goal and needs?) were also included in the questionnaire. The answers acquired have been reflected in the Figure 2 "'Evaluation of aims and results".

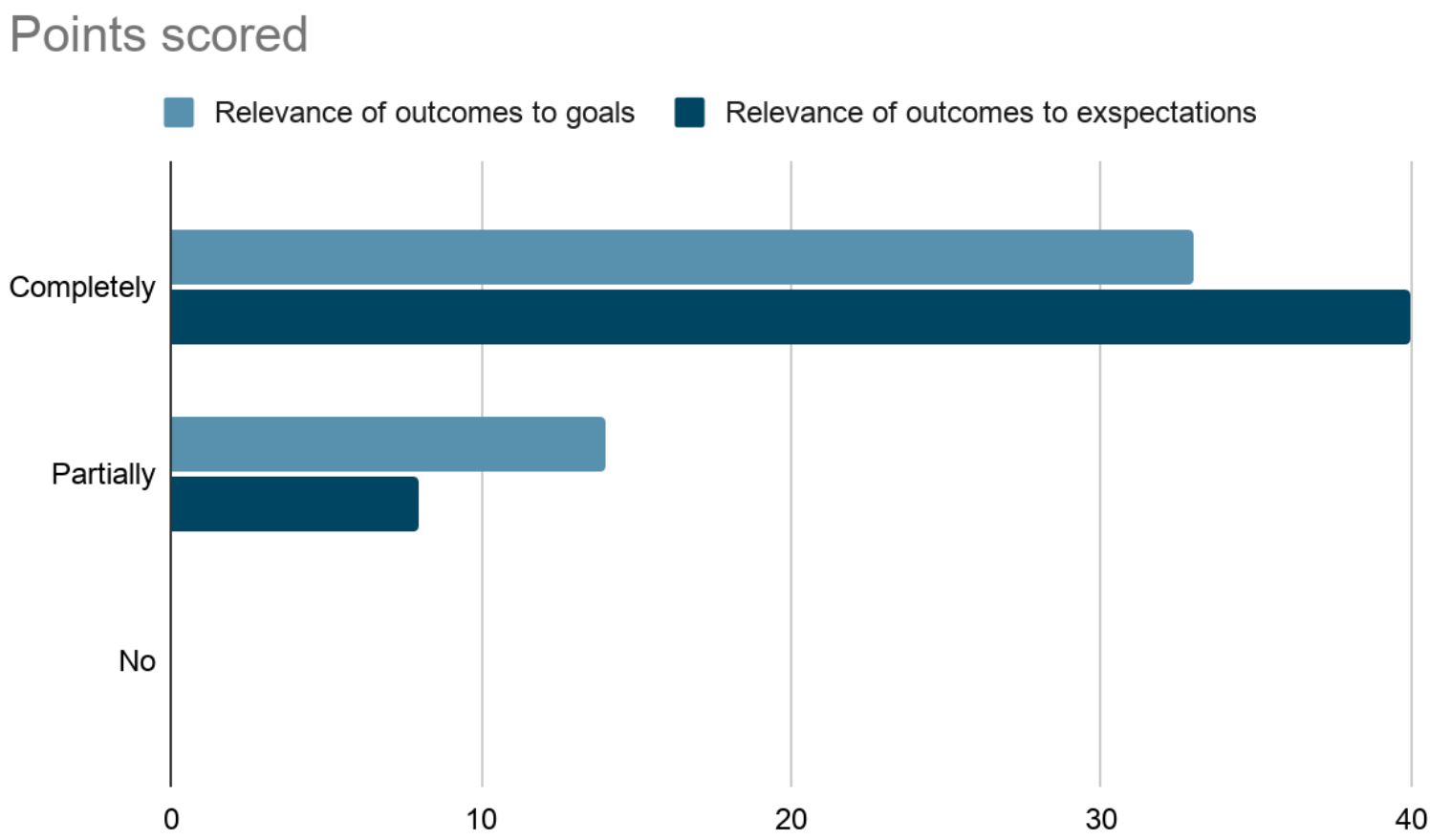

Figure 2 Evaluation of Aims and Results

One of the most essential things for motivation is a clear, timely, and fair assessment. The evaluation system needs to be explained at the very beginning of the course. Since the course has been developed entirely in English, taking into account the level of preparation of prospective students, written instruction for the course in Russian has been developed. The evaluation system has been explained in this instruction to avoid any misunderstanding. Learners focus on 
what they need to do to pass. Developing learning activities, it is necessary to ensure that intended learning outcomes relate to the appropriate assessment task. Assessment as part of learning is the way to show students their progress and encourage them. At the end of every week, students have a formative test to provide ongoing feedback and help them to identify their strengths and weaknesses. For each topic, summative tests have been developed to evaluate students' achievements. The course ends with a final test, which determines whether students have learned what they are expected to learn and evaluates the effectiveness of educational programmes. The results of the questionnaire also revealed that the assessment of knowledge and skills during the course acquisition period has been correspondingly objective (Figure 3).

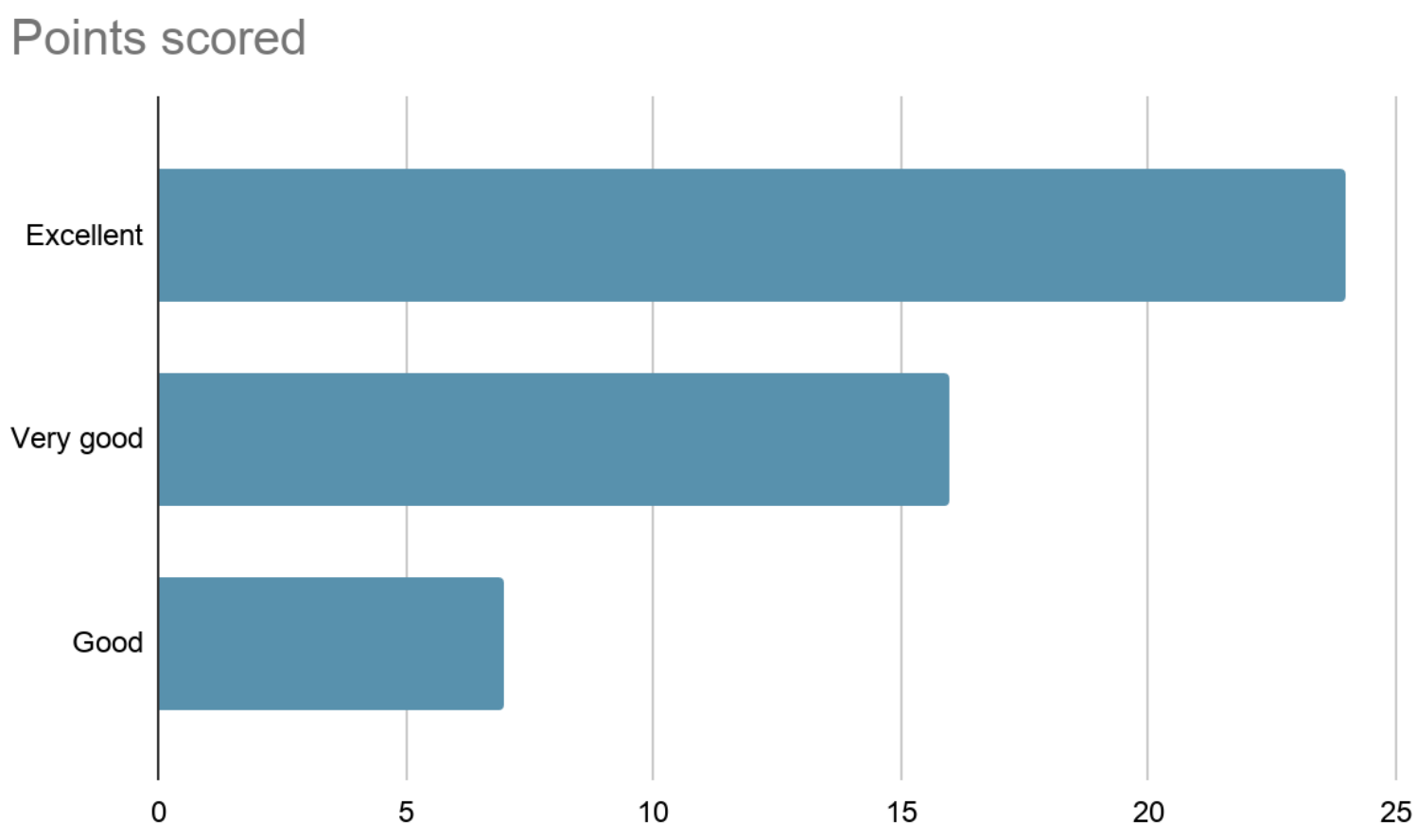

Figure 3 Appropriate Assessment of Knowledge and Skills

Everything works for this aim materials, structure, teaching methods and tools, assessment, and evaluation. Enrolling the course prospective students usually have some expectations. The best way to meet them is to describe the course at the very beginning, present clearly the intended learning outcomes, and explain the evaluation system. Doing the online course, students have quite a limited contact with the teacher so they may feel abandoned. The participants of the questionnaire have also pointed it out. Short encouraging reactions to fulfilled exercises and daily feedback help to avoid this and allow the teachers to evaluate the materials' quality and promptly identify any problems.

In general the focus group evaluated the development of the foreign language competence in the following fields: vocabulary knowledge has increased, grammar knowledge has become broader, the ability to comprehend 
The Development of the Online Foreign Language Course - the Experience of the Bell Project

the content of the text without the usage of additional resources has developed, comprehension on the English language has improved, the perception of the spoken text has been perfected, the skill to use other online resources in the foreign language acquisition has been developed, practically useful topics have been acquired. However, one of the main conclusions of the online course participants' is a perspective to use acquired in knowledge in the future.

\section{Conclusions}

Summarising the results of the research and questionnaire as well as the project experience based on theory and practice, it is possible to define the following most essential criteria - reference points, which can be generally applied, working out the online course for the foreign language. They can be advised to those who have intended to work it out:

- $\quad$ Detailed planning has to be done before working out of the course, its conception has to be comprehended (specifics of the focus group), the aim of the course, the methods used, the results to be achieved, and the methods of their measuring and evaluation, providing feedback);

- $\quad$ The content of the online course is structured accordingly, in addition taking into consideration the total number of the classes, in which students' independent work has been included;

- The tasks have to be functional, relevant, developed using digital options and concerned with additional materials on the Internet;

- $\quad$ To occasionally integrate online and face-to-face classes (at least to provide an opportunity for the students who can attend them at the particular time) during the online courses' period when the learners devote most of their time to independent work.

- The content of learning materials must respect copyright and be engaging, relevant, and up- to-date.

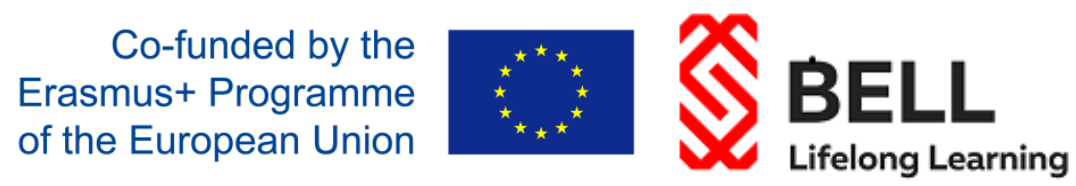

The European Commission's support for the production of this publication does not constitute an endorsement of the contents, which reflect the views only of the authors, and the Commission cannot be held responsible for any use which may be made of the information contained therein.

\section{References}

Celce - Murcia, M. (2001). Teaching English as a Second Foreign Language. London: Heinle \& Heinle.

Riemer, C. \& Wild, K. (2018). Individuelle Einflüsse auf den Fremdsprachenerwerb Einführung in das Themenfeld. ResearchGate.. DOI: 1031816/Dhoch3.2018.82 